\title{
Platform Organization of Digital Accounting
}

\author{
Evgenij Yur'evich Moskvitin*
}

\author{
Don State Technical University in Shakhty, Shahty, Russia \\ *Corresponding author. Email: djulm@rambler.ru
}

\begin{abstract}
The concept of platform accounting architecture is given. "Digital platform for accounting and predetermined analysis" and "Organization of digital accounting" patterns are developed and patented. Business models of digital accounting of an individual entrepreneur, small, medium and large enterprises are provided. Synergistic mega-balance.
\end{abstract}

Keywords: Pattern, digital platform and accounting, digital technologies and tools, digital business models, synergistic effect.

\section{INTRODUCTION}

The basis of digital accounting is the platform organization of all types of activities and all processes.

The foundation of digital accounting includes: big data, a database, an engineering chart of accounts, digital technologies and a system of algorithms that create new intangible assets, which currently amount to about $\$ 80$ trillion (Fig. 1).

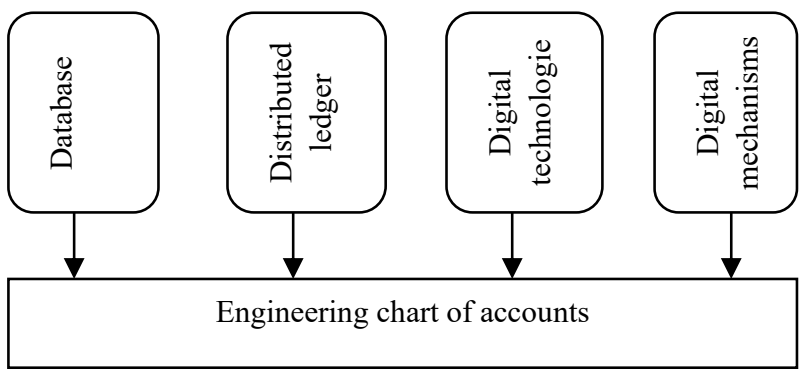

Figure 1 The foundation of digitalization.

The cost of big data i.e. the foundation of digitalization of any process and object is determined by the components:

- the cost of intangible assets;

- the cost of the owner's activity;

- the cost of changing the value of information.

The value of the platform is determined by the factors that together create a synergistic effect, determined on the basis of the digital synergistic magabalance, patented in the Rospatent of the Russian Federation by Professor V.I. Tkach.
The platform organization of accounting ensures the functioning of dozens of digital technologies and hundreds of mechanisms that create a management system and predictive analytics for use of the Capital (financial, social, intellectual, environmental, etc.) in a sustainable development (backup system, risks).

\section{ANALYSIS OF RECENT RESEARCH, PATENTS AND PUBLICATIONS}

A large group of researchers deals with the problems of the theory of organization and methodology of the digital economy $(1,4,11,18,21,23,28,44,51,57,60$, $64,66,67)$. Theoretical issues of digital accounting and predictive analytics have been considered in numerous works in Russia and abroad (7, 12, 14, 21, 23, 27, 44, 45, $46,49,50,54,69)$. Various theoretical aspects of digital accounting and their types (engineering, hedged, triple, three-level, mega, stereo) are considered in works $(5,13$, $15,16,18,19,20,34,35,44,47,58,61)$.

The construction, architecture, design, analysis and non-use of financial, immunization, hedged, social, environmental, strategic, transactional, fractal accounting and analytical technologies are considered in works $(2,6,8,21,27,30,31,36,37,40,53,62)$.

Digital tools, their design and use are presented in the works of many authors $(3,10,19,22,26,32,42,55)$.

\section{PLATFORM ARCHITECTURE}

Currently, the world economy and Russia have developed thousands of platforms, which are classified into groups: management, instrumental, infrastructural, 
behavioral, applied, auditing, analytical, accounting ones $[6,17,18,39,41,65,68]$.

The scientific school of the honorary professor of DSTU V.I. Tkach developed a set of platforms: an engineering chart of accounts of a commercial enterprise; engineering chart of accounts of a budgetary organization; engineering chart of accounts of the university; digital behavioral platforms $[2,5,6,13,16$, $18,19,24,30,32]$.

Digital platforms in behavioral economics are formed at five levels: microeconomics (behavior of individuals); megaeconomics (behavior of commercial enterprises); meta-economics (behavior of budgetary organizations); mesoeconomics (industry behavior); macroeconomics (behavior of state governing bodies).

Digital management platforms are formed in a multilevel context: an individual, entrepreneurs, commercial enterprises, and etc.

In the process of developing digital platforms, the architecture of the chart of accounts and the corresponding behavioral, management platform was taken as a basis: economic; engineering; instrumental; integral; adaptive; structural ones, and etc.

Economic architecture considers the following:

- methods for determining financial results: balance, net assets, operational, economic, reflecting and management;

- methods of determining ownership: net assets, net liabilities in adequate estimates.
Structural architecture includes: activities; internal segments; cost centers; outer segments; different situations; events, facts of economic activity; directions of strategic activity; product life cycle; value chain; time fractals; cost elements.

Engineering architecture: mega-accounts; synthetic accounts; sub-accounts of the 1st - 4th orders.

Instrumental architecture (system of digital mechanisms): situational; behavioristic; organic; substantive; hedged; integrated risk; immunization; monitoring; social; synergistic; reorganization; recreational; actuarial; subsidiary; investment; fractal; strategic; semantic; venture; innovative; tactical; equilibristic, and etc. There are about 500 positions in total.

Integration architecture: transactional; managerial; strategic; adaptive; social; situational; value chain; functional; tax; standard costing; direct costing and other types of accounting.

Adaptive architecture: flexible IT/C; situational transactions; extended capabilities; predictive support; strategic management; tactical management; operational management; effective use of information resources; control; financial improvement; management and strategic accounting; integrated architecture $[13,21,56$, $59,63]$.

The architecture of the engineering chart of accounts is focused on ensuring control of property indicators in accordance with the requirements of the 1st and 2 nd laws of a market economy, i.e. net assets and net liabilities in adequate estimates (Fig. 2).

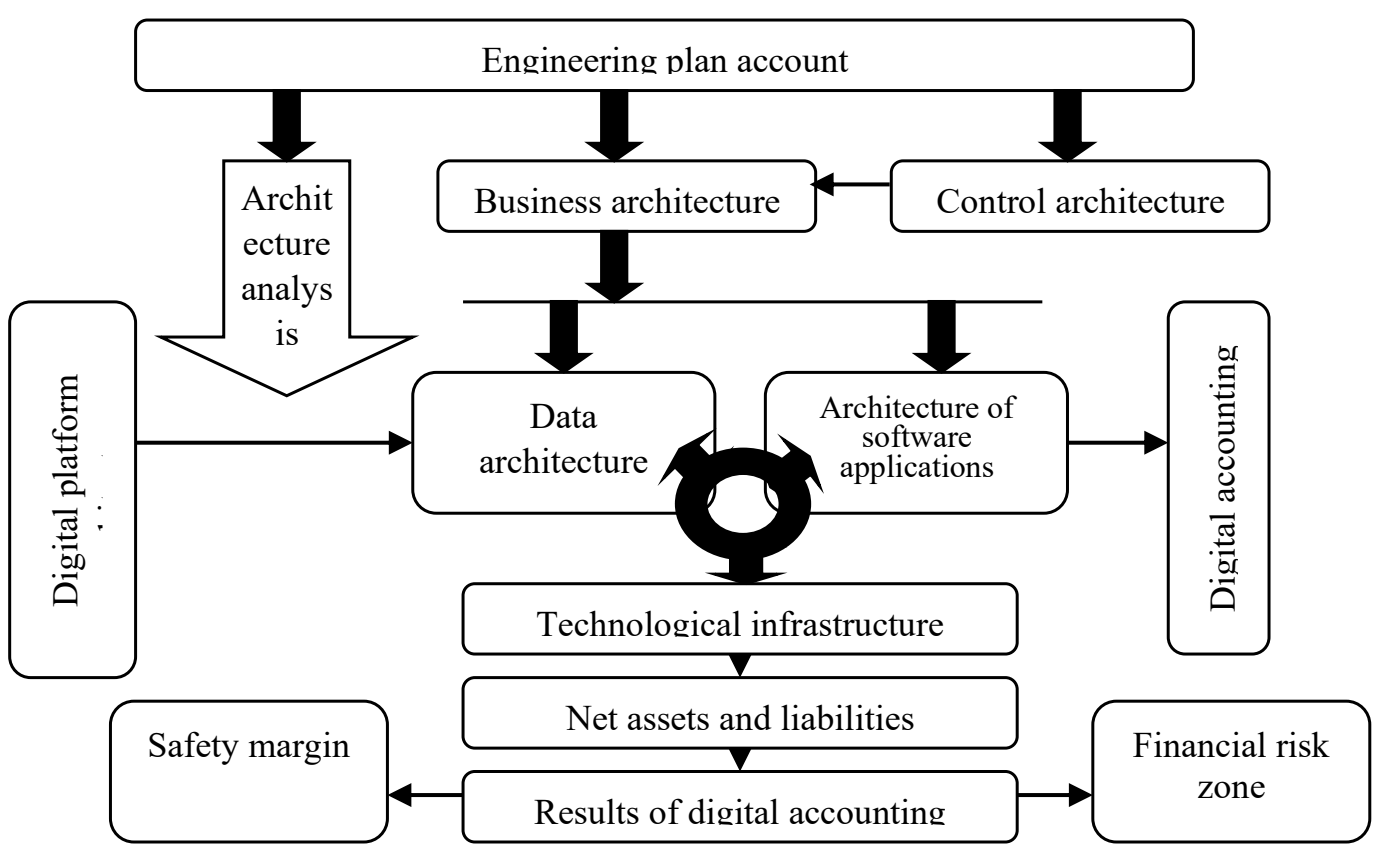

Figure 2 Architecture concept. 
In general, the architecture of the engineering chart of accounts harmonizes the economic, engineering, accounting, instrumental and integration business structure towards creating a digital accounting, control, analysis and synergy management platform.

The digital accounting architecture creates a system of interfaces and operators of the registering system (blockchain, transaction log) with digital programs, an engineering chart of accounts, digital tools, stakeholders with modules of net assets and net liabilities as the main indicators of ownership and capital.

\section{DIGITAL PLATFORM PATTERN}

The digital accounting and analysis platform architecture focuses on equity metrics (net assets at market value and net liabilities at fair value).

Structurally, these indicators are represented by three formulas:

1) the basic balance sheet equation: Assets = Capital + Liabilities;

2) sections of the balance sheet: Capital $=($ Assets 1 section + Assets 2 section of the balance sheet) - (Longterm liabilities + Short-term liabilities);

3) sections of the chart of accounts: Capital (section $\mathrm{VII})=[$ Non-current assets $($ Section I) + Inventories (Section II) + Production Costs (Section III) + Finished Goods (Section IV) + Cash (Section V)] \pm Calculations (Section VI) \pm Financial Results (Section VIII).
As a result, a digital information platform and a set of platform solutions for enterprises of any form of ownership and size can be represented by pattern data (Fig. 3).

The pattern provides the construction of any of 6 types of digital accounting: triple, mega, hedged, threelevel, stereo and engineering one [44].

The thing is that any digital accounting is an accounting system operating on the basis of a digital platform and a complex of digital technologies and mechanisms that provides online management of all types of capital (financial, intellectual, human, environmental, social) with a focus on safety margin and synergistic effect based on use of the digital infrastructure $[13,15,16,19,34,44,47]$ : digital megaaccounts; algorithms; big data; predictive analytics; cloud computing; digital technologies; mobility (fractals of time); geolocation (territorial fractals); social networks; internet of things; artificial intelligence; machine learning (supreme algorithm).

The mega-account system is represented by 3 options focused on the market and fair systemicity of capital:

1. Triple, mega, three-level, stereo accounting, based on three mega-accounts, under a variety of designations, suggested for the first time by

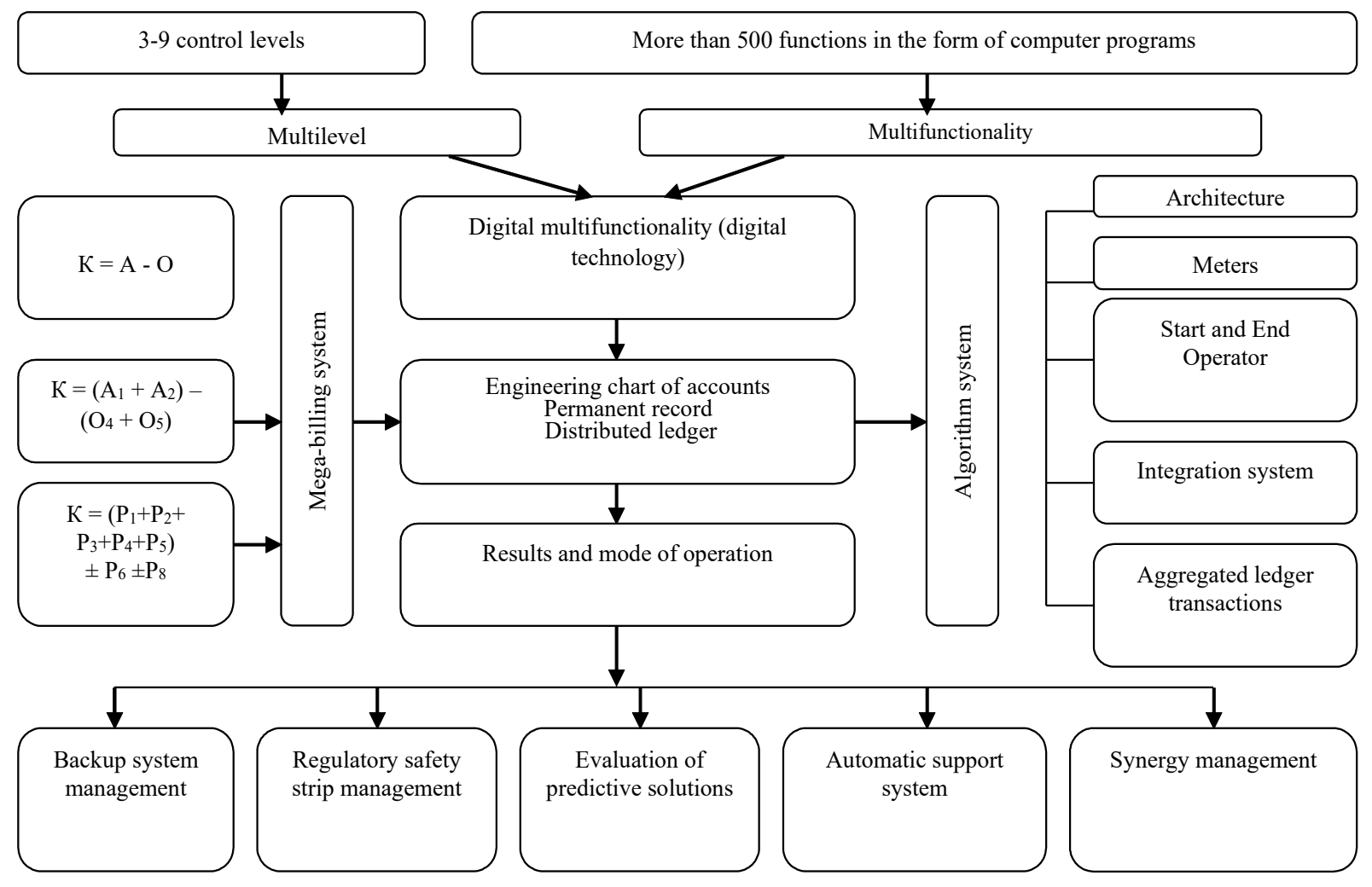

Figure 3 "Digital Accounting Platform" Pattern 
F. Ezersky in triple Russian accounting and recommended by the World Congress of Accountants in Amsterdam (1912) for use in all countries:

a) Cashier; Property; Capital;

b) Debit; Credit; Trebit;

c) Asset; Obligations; Capital.

2. Hedge accounting operates on the basis of megaaccounts, representing sections of the balance sheet.

3. Engineering accounting is focused on use of sections of the engineering chart of accounts, which allows the use of more than 500 digital mechanisms that were not previously used in management by traditional accounting.

The "Digital Accounting Platform" pattern forms the foundation of business models for functioning of subjects of a behavioral market economy [38].

\section{BUSINESS MODEL OF DIGITAL ACCOUNTING}

A digital accounting platform is at the core of any business model:

- $\quad$ Individual entrepreneur and small business.

- Medium and large business.

- Budgetary organizations.

- Municipalities.

- $\quad$ Targeted programs, grants.

- National and federal programs.

The digital platform is formed by 3 mega-accounts: A $=\mathrm{K}+\mathrm{O}$.

A - assets;

$\mathrm{K}$ - capital;

\section{$\mathrm{O}-$ obligations.}

This business model does not involve use of an engineering chart of accounts, but is designed around a permanent record and database (proprietary, private, national or international).

The business model provides for use (5-17) of realtime accounting and analysis programs:

- $\quad$ financial condition;

- $\quad$ solvency;

- $\quad$ backup system;

- $\quad$ management of risks;

- $\quad$ property;

- a set of tax accounting programs.

All programs were developed in the scientific school of the Honorary Professor of DSTU Tkach V.I. and are registered with Rospatent.

The business model of digital accounting and instant analysis of an individual entrepreneur can be used by 3.7 million individual entrepreneurs of Russia, with an average cost of a complex of digital programs of 17 thousand rubles and will create an opportunity in the conditions of three-tier accounting and the national Internet of the Russian Federation (introduced from 01.01.2021) for the functioning of the all-Russian control over tax payments, which will lead to an increase in the revenue side of the budget by 1.7 trillion. rub.

The general model of digital accounting for medium and large businesses is represented by the data in Figure 5 .

The business model of digital accounting and predictive analysis of the activities of an individual entrepreneur and small business is presented by the data in Figure 4.

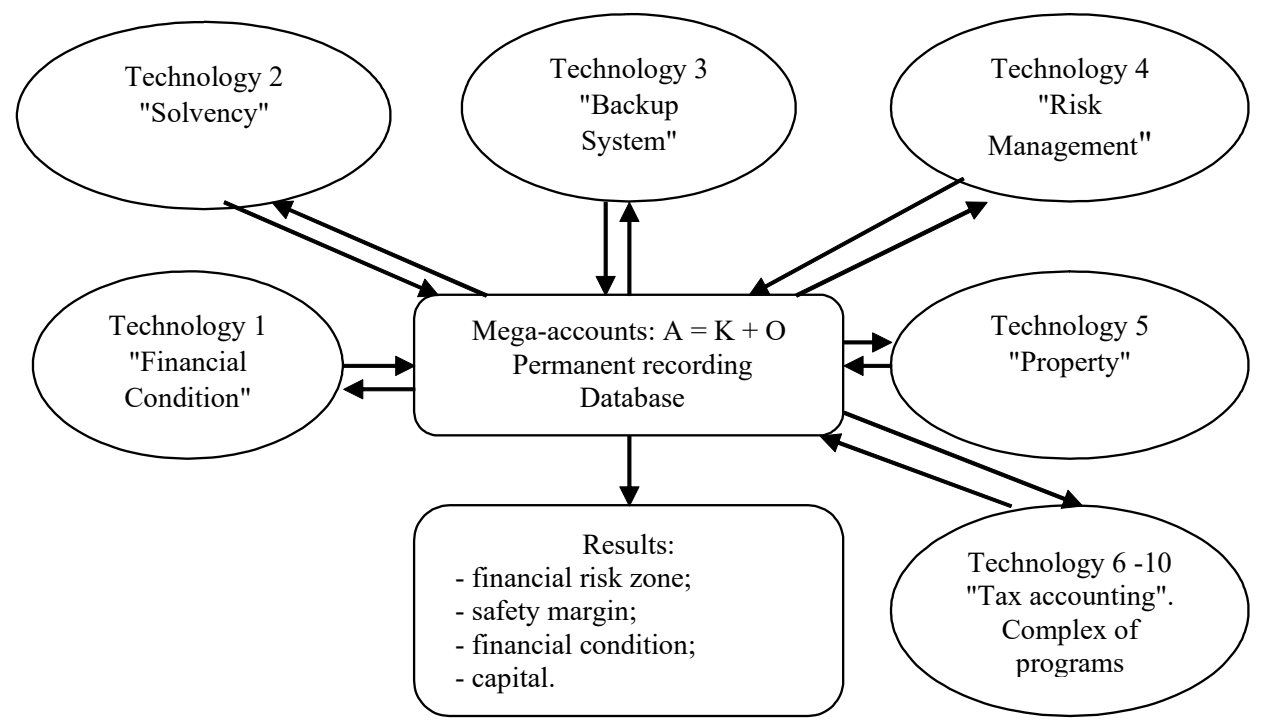

Figure 4 The business model of digital accounting and predictive analysis of the sole proprietor and small business 


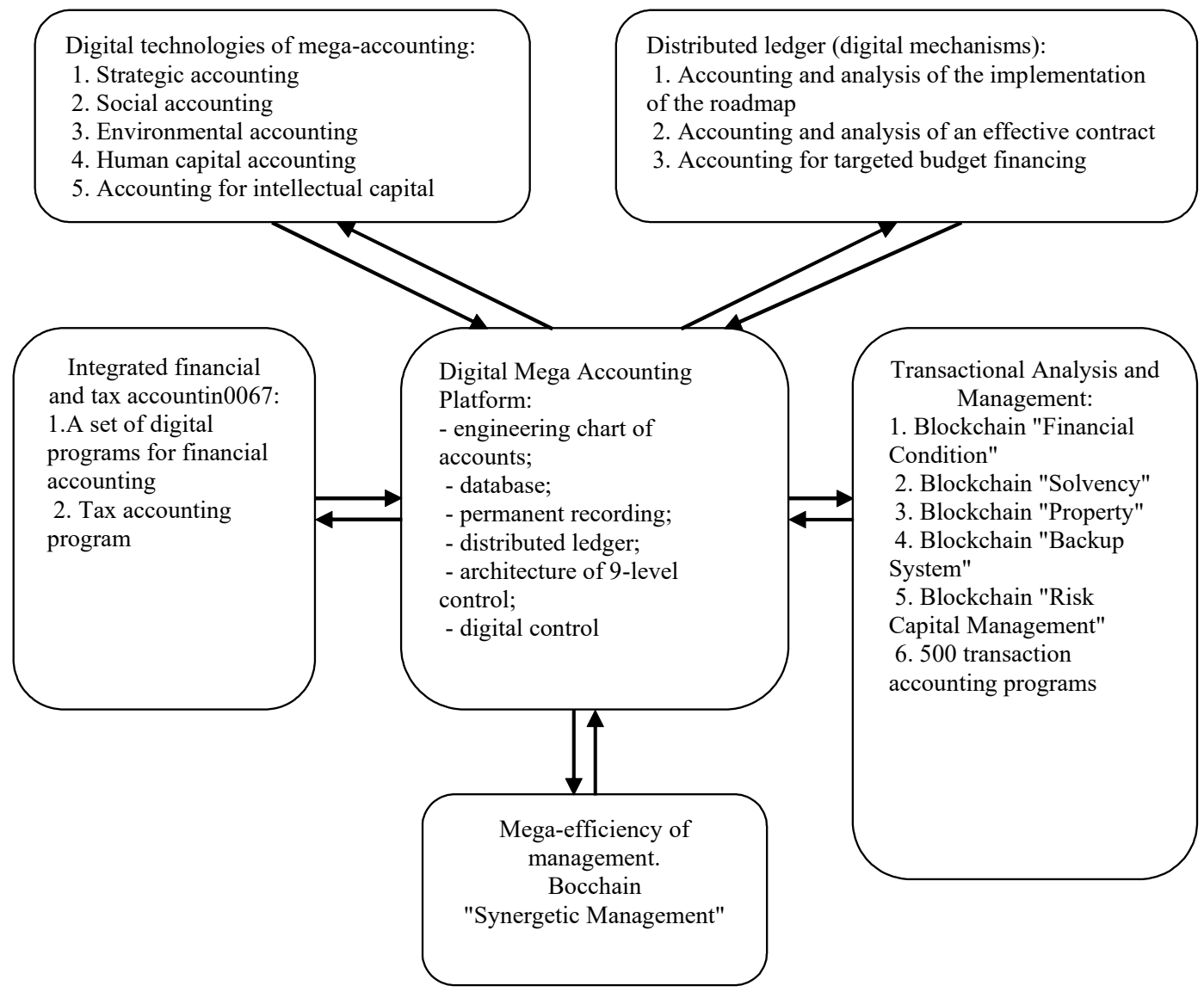

Figure 5 Business model of digital accounting for medium and large businesses

Digital accounting platform for medium and large businesses includes:

- $\quad$ engineering chart of accounts;

- database;

- $\quad$ permanent records;

- $\quad$ distributed ledger;

- $\quad$ architecture of 9 control levels;

- digital control.

4 accounting and analytical systems operate on the basis of the digital platform:

\section{Financial and tax accounting:}

1. A complex of digital technologies and financial accounting mechanisms.

2. Digital technology and tax accounting mechanism.

II. Digital technologies of mega-accounting:

1. Strategic accounting.

2. Social accounting.

3. Environmental accounting.

4. Human capital accounting.

5. Accounting for intellectual capital accounting.

6. Other types of capital: structural; behavioristic; consumer; educational; ecological.
Digital accounting and control programs operate on a platform basis, i.e. are used by the management of the enterprise and do not require the creation of special structures and personnel, since operate in real time, as necessary, several hours a month.

III. The distributed ledger system includes digital mechanisms that allow you to determine and use in online management the results in the context of employees, departments, services, etc.

1. Accounting and analysis of the implementation of the roadmap.

2. Accounting and analysis of the implementation of an effective contract.

3. Accounting and analysis of targeted budget financing, reflecting the results obtained:

- $\quad$ created assets: social (A s), intellectual (Ai), educational (Ae), etc.;

- $\quad$ created capital: social (Ks), intellectual (Ki); ecological (Ke), etc.;

- obligations: social (Os), intellectual (Oi); ecological (Oe), and etc.

As a result, a digital system functions that provides management of any type of capital:

- $\quad$ social Ks = As - Os;

- $\quad$ intellectual: $\mathrm{Ki}=\mathrm{Ai}-\mathrm{Oi}$; 
- $\quad$ educational: $\mathrm{Ke}=\mathrm{Ae}-\mathrm{Oe}$.

IV. Transactional analysis and management based on a system of digital mechanisms:

- financial condition of competitors and partners;

- $\quad$ solvency of individuals, entrepreneurs, contractors; stakeholders, and etc.

- $\quad$ property in the form of net assets at market value and net liabilities at fair value at any level;

- $\quad$ backup system and safety margin;

- $\quad$ synergistic effect;

- $\quad$ any other transaction indicators for which in engineering and three-level accounting there are more than 500 computer programs operating on a platform principle, i.e. do not require the creation of special structures and appropriate personnel [2, 19, 20, 44].

The results of functioning of the digital business model of the enterprise are reduced to positioning of finance and accounting at the level of the 1st highest category of management:

1. Mega efficiency of management:

- for any type of capital, not just financial (structural, behavioral, social, environmental, etc.);

- $\quad$ any type of 9 management levels;

- provides implementation of the pattern "Platform organization of digital accounting" (Table 1).
- creates an opportunity to manage the solvency of any participant in market relations: an individual, an entrepreneur, a commercial enterprise, a budgetary organization, etc.

- $\quad$ - digital accounting ensures the predetermining nature of management for any decision with the definition of the zone and margin of economic security and strategic orientation of security.

In general, the platform organization of accounting, control and analysis includes:

- $\quad$ engineering chart of accounts;

- $\quad$ permanent records;

- database;

- $\quad$ distributed ledger;

- 9-level management architecture;

- $\quad$ digital control;

- $\quad$ a set of digital programs for financial and tax accounting;

- $\quad$ complex of mega-accounting programs;

- distributed ledger and blockchain system for roadmap control, effective contract, targeted funding, etc.

- $\quad$ transactional analysis and management;

- $\quad$ organization of synergistic management.

The platform organization of accounting, analysis and control ensures implementation of the fundamental postulates of digitalization: optimum, equilibrium and synergy of participants in market relations reflected by any of the 6 digital accounting systems [44].

Table 1. Pattern "Platform organization of digital accounting"

\begin{tabular}{|c|c|c|c|c|c|c|c|c|c|c|c|}
\hline \multirow[b]{2}{*}{$\begin{array}{c}\text { Platform } \\
\text { qualimetry } \\
\text { Types of platform } \\
\text { solutions }\end{array}$} & \multirow[b]{2}{*}{ 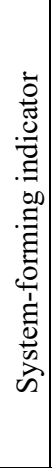 } & \multirow[b]{2}{*}{ 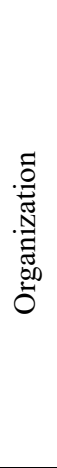 } & \multirow[b]{2}{*}{ 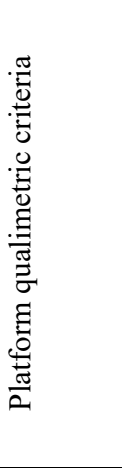 } & \multicolumn{3}{|c|}{ The digital paradigm } & \multicolumn{4}{|c|}{ Results and platform solutions } & \multirow[b]{2}{*}{$\begin{array}{l}\text { Digital } \\
\text { control }\end{array}$} \\
\hline & & & & 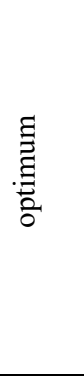 & 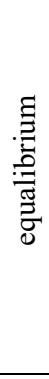 & 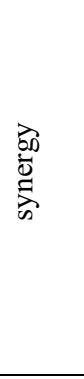 & 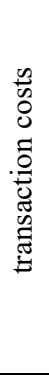 & $\frac{n}{n}$ & 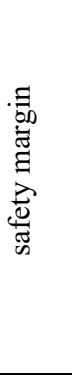 & 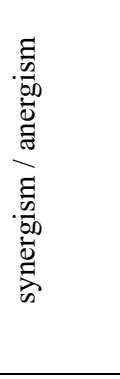 & \\
\hline 1 & 2 & 3 & 4 & 5 & 6 & 7 & 8 & 9 & 10 & 11 & 12 \\
\hline $\begin{array}{l}\text { 1. Instrumental } \\
\text { 2. Infrastructure } \\
\text { 3. Accounting: } \\
\text { micro, } \\
\text { mega, meta, meso, } \\
\text { macrolevel } \\
\text { 4. Transactional }\end{array}$ & 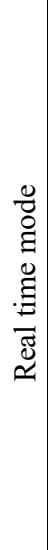 & 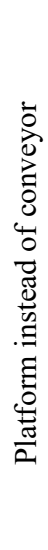 & 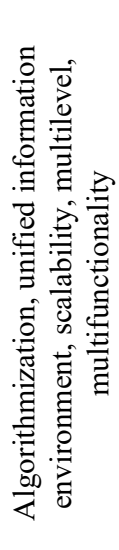 & 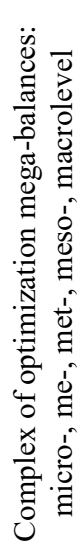 & 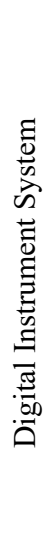 & 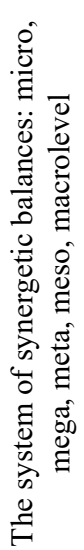 & 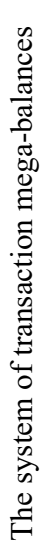 & 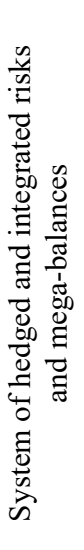 & 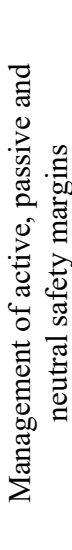 & 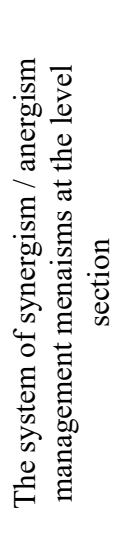 & 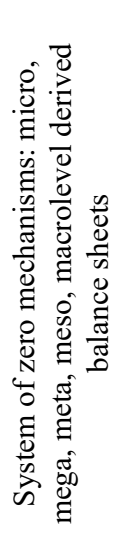 \\
\hline
\end{tabular}




\section{REFERENCES}

[1] M.Yu. Anikeev, Accounting and economic treatment of hedging processes. Collection of scientific articles "New directions of accounting and auditing at the present stage of economic development". Rostov-on-Don: RSSU, 2005, pp. 181-198.

[2] K.S. Blagovisnaya. Organization of hedge accounting at the enterprise: Study Guide, Rostovon-Don: DSTU, 2017, pp. 62.

[3] I.A. Blank, Asset management, Kiev: Nika - Center, 2000, pp. 720.

[4] E. Gamma, R. Helm, R. Johnson, J. Vlissides. Object-oriented design techniques. Design patterns. SPb.: Peter, 2018, pp. 368.

[5] J. Garaedagi. Systems thinking: How to manage chaos and complex processes: A platform for modeling business architecture, Jamshid Garaedagi; translated from English. E.I. Nedbalskaya; Minsk: Grevtsov Books, 2010, pp. 480.

[6] A. Daile. Controlling Practice: Transl. from German, M.: Finance and Statistics, 2003, pp. 336.

[7] S. E. Dubova, Analysis of risk-forming factors in the risk management system, Finance and Credit, 7(211) (2006) pp. 38-45.

[8] S. Zeff, Payton Williams Andrew, Classics of Management, SPb.: Peter, 2001, pp. 1168.

[9] Yu. A. Ilstein, Accounting and control of enterprise value as: RSSU, 2006, pp. 292.

[10] E. Campbell, Strategic synergy. SPb.: Piter, 2004, pp. 416.

[11] O. M. Kolvakh. Situational matrix modeling in accounting and balancing: monograph, M.: Vuzovskaya kniga, 2010, pp. 336.

[12] R. Koch, Strategy: How to create and use a strategy, 2nd ed. R. Koch. SPb.: Piter. pp. 320.

[13] V. V. Krokhicheva, Databases of information accounting systems. Improving accounting, analysis and auditing in a market economy. Collection of scientific articles. Rostov-on-Don: RSSU, 2004.

[14] V. V. Krokhicheva, Accounting for the backup system. The development of accounting in the modern economy of Russia: Collection of scientific articles. Rostov-on-Don: RSSU, 2005.

[15] E. V. Kuznetsova System of charts of accounts and accounting management of economic processes: monograph, Rostov-on-Don: SFedU Publishing House, 2010, pp. 352.
[16] D. V. Kurseev, Accounting model of enterprise property management as a property complex, Accounting and analysis in the enterprise management system. - Rostov-on-Don: Rostov State University of Civil Engineering, 2005, pp. 208.

[17] V. V. Lesnyak, Strategic management accounting in industrial enterprises: a conceptual approach, modeling and organization. - Rostov-on-Don, RSSU, 2005, pp. 195.

[18] I. V. Lesnyak, Situational analysis and control in commercial organizations. Rostov-on-Don, RSSU, 2009, pp. 190.

[19] Li Guojie, Digital Economy Drives Innovative Development (N), People's Daily, 2016.

[20] Mainzer Klaus, Complex system thinking: Matter, mind, humanity. New synthesis. M.: LIBROKOM Book House, 2009, pp. 464.

[21] M. Blaug, 100 Great Economists After Keynes, SPRb.: School of Economics, 2005, pp. 352.

[22] J. F. Marshall, V. K. Bansal, Financial Engineering: A Complete Guide to Financial Innovation, M.: INFRA-M, 1998, pp. 784.

[23] G. Mintzberg. Strategic process, SPb.: Piter, 2001, pp. 686.

[24] G. Mintzberg, Schools of strategies, SPb.: Piter, 2000, pp. 336.

[25] V. F. Paliy, Accounting theory: modern problems. M.: Publishing house "Accounting", 2007, pp. 88.

[26] B. M. Rapoport, A.I. Subchenko, Engineering and business modeling. M.: Tandem, 2001, pp. 282.

[27] R. S. Rashidov, Logical and mathematical modeling in accounting, M.: Finance, 1979, pp. 128.

[28] V. I. Tkach, G. E. Krokhicheva, The system of zero derivative balance sheets and their use in management, Economic analysis: theory and practice, 12 (2004) pp. 6-13.

[29] L.G. Golovach, M.L. Lukashevich, Han Dietger Hungenberg Harald $P$ and K. Value-Based Controlling Concepts: Transl. from German, M.: Finance and Statistics, 2005, pp. 928.

[30] J. Hirshleifer, Investment decisions under uncertainty: approaching from the point of view of the theory of choice, Milestones of Economic Thought. Production Factor Markets. SPb.: Economic School, 2000, pp. 489 p.

[31] E. Campbell, K. Summers Lachs Strategic Synergy, 2nd ed., SPb.: Piter, 2004, pp. 416. 
[32] R. J. Eccles, R. H. Hertz, E. M. Keegan, D. M. H. Phillips, Revolution in corporate reporting: How to talk to the capital market in the language of value, not profit, M.: "Olimp-Business", 2002, pp. 400.

[33] D. Moshella, Guide to the digital future: Industries, organizations and professions, M.: Alpina Publisher, 2020, pp. 215.

[34] V.V. Pigunova, Application of engineering systems in accounting for the solvency and financial stability of an enterprise: textbook. Guide book, Don state tech. un-ty - Rostov-on-Don: DSTU, 2017, pp. 55.

[35] V.I. Tkach, Digital behavioral economics: technologies and platform solutions: textbook, Don state tech. un-ty. Rostov-on-Don: DSTU, 2019, pp. 482.

[36] V.I. Tkach. University: engineering management: qualimetric monograph. Rostov-on-Don: Publishing Center DSTU, 2016, pp. 379.

[37] M. N. Clemente and D. S. Greenspan, Winning at Mergers and Acquisitions: The Guide to MarketFocused Planning and Integration, New York; John Wiley \& Sons 1998, pp. 46.

[38] M. Knickrehm, B. Berthon,' P.Daugherty. Digital Disruption: The Growth Multiplier (R). Accenture Strategy, 2016.

[39] World Economic Forum. He Global Information Technology Report 2016: Innovating in the Digital Economy (R). 2016. 